The University of Maine

DigitalCommons@UMaine

Earth Science Faculty Scholarship

Earth Sciences

$9-1-2006$

\title{
Calving Giant Icebergs: Old Principles, New Applications
}

James P. Kenneally

Terence J. Huges

University of Maine - Main, terry.hughes@maine.edu

Follow this and additional works at: https://digitalcommons.library.umaine.edu/ers_facpub Part of the Earth Sciences Commons

\section{Repository Citation}

Kenneally, James P. and Huges, Terence J., "Calving Giant Icebergs: Old Principles, New Applications" (2006). Earth Science Faculty Scholarship. 20.

https://digitalcommons.library.umaine.edu/ers_facpub/20

This Article is brought to you for free and open access by DigitalCommons@UMaine. It has been accepted for inclusion in Earth Science Faculty Scholarship by an authorized administrator of DigitalCommons@UMaine. For more information, please contact um.library.technical.services@maine.edu. 


\title{
Calving giant icebergs: old principles, new applications
}

\author{
J.P. KENNEALLY ${ }^{1,2}$ and T. HUGHES ${ }^{2,3}$ \\ ${ }^{1}$ Department of Physics, University of Maine, Orono, ME 04469-57790, USA \\ ${ }^{2}$ Climate Change Institute, University of Maine, Orono, ME 04469-57790, USA \\ ${ }^{3}$ Department of Earth Sciences, University of Maine, Orono, ME 04469-57790, USA
}

\begin{abstract}
Earth-orbiting satellites can now monitor calving of large icebergs from ice shelves bordering the marine West Antarctic Ice Sheet, and recent calving events have stimulated interest in calving mechanisms. To advance this interest pioneering work in brittle and ductile fracture mechanics is reviewed, leading to a new application to calving of giant icebergs from Antarctic ice shelves. The aim is to view iceberg calving as more than terminal events for Antarctic ice when glaciologists lose interest. Instead calving launches Antarctic ice into the larger dynamic system of Earth's climate machine. This encourages a holistic approach to glaciology.
\end{abstract}

Received 10 May 2005, accepted 11 January 2006

Key words: climate, glaciology, West Antarctic Ice Sheet

\section{Introduction}

In the last three decades, major calving events shown in Fig. 1 have taken place in the large ice shelves that form when the marine West Antarctic Ice Sheet, grounded up to $2.5 \mathrm{~km}$ below sea level, becomes afloat in deep water around its northern, eastern, and western perimeter. These events began inauspiciously in 1989 with complete disintegration of the small Wordie Ice Shelf on the west side of the Antarctic Peninsula (Doake \& Vaughan 1991) followed by partial disintegration of George VI Ice Shelf in 1995 and Wilkins Ice Shelf in 1998 (Scambos et al. 2000). Disintegration of the much larger Larsen Ice Shelf on the east side of the Antarctic Peninsula began in 1995 (Rott et al. 1996) and has been propagating southward, with the central portion disintegrating catastrophically within days during 2002, and the remaining portion now showing early signs of disintegration (De Angelis \& Skvarca 2003). The largest calving events have been from the huge ice shelves on the eastern and western flanks of the West Antarctic Ice Sheet. Enormous icebergs calved from the Filchner Ice Shelf north of the Grand Chasms in 1986 (Ferrigno \& Gould 1987), from the Ronne Ice Shelf in 2002, as predicted by Rignot \& MacAyeal (1998), and from the Ross Ice Shelf in 1987 (Keys et al. 1998), in 2000, and in 2002, as predicted by Lazzara et al. (1999). In the Amundsen Sea sector, Thwaites Iceberg Tongue, $100 \mathrm{~km}$ long, was released from its moorings in 1986 (Lucchitta et al. 1994). The floating tongues of both Thwaites Glacier and Pine Island Glacier calved in 2002 (Rabus et al. 2003).

These calving events have occurred at a time when rapid melting rates have been observed on Antarctic ice shelves (Scambos et al. 2000), especially bottom melting (Rignot \& Jacobs 2002), often associated with rapid retreat of ice-shelf grounding lines (Rignot 1998a, 1998b, 2001, 2002, Thomas et al. 1998, Bindschadler \& Vornberger 1998) and downdraw of interior ice (Bindschadler 1997, 1998, Shepherd et al. 2001, Zwally et al. 2002, De Angelis \& Skvarca 2003). These observations link large-scale calving to long-term instability of the West Antarctic Ice Sheet (Conway et al. 1999) that may point to substantial gravitational collapse and a rise in sea level of up to $5 \mathrm{~m}$, perhaps in this century (Mercer 1978, Thomas et al. 1979, Hughes 1981). Climatic changes may take place as these giant icebergs enter the Southern Ocean and melt by extracting heat from the CircumAntarctic Current (Anderson 1999, fig. 1.21).

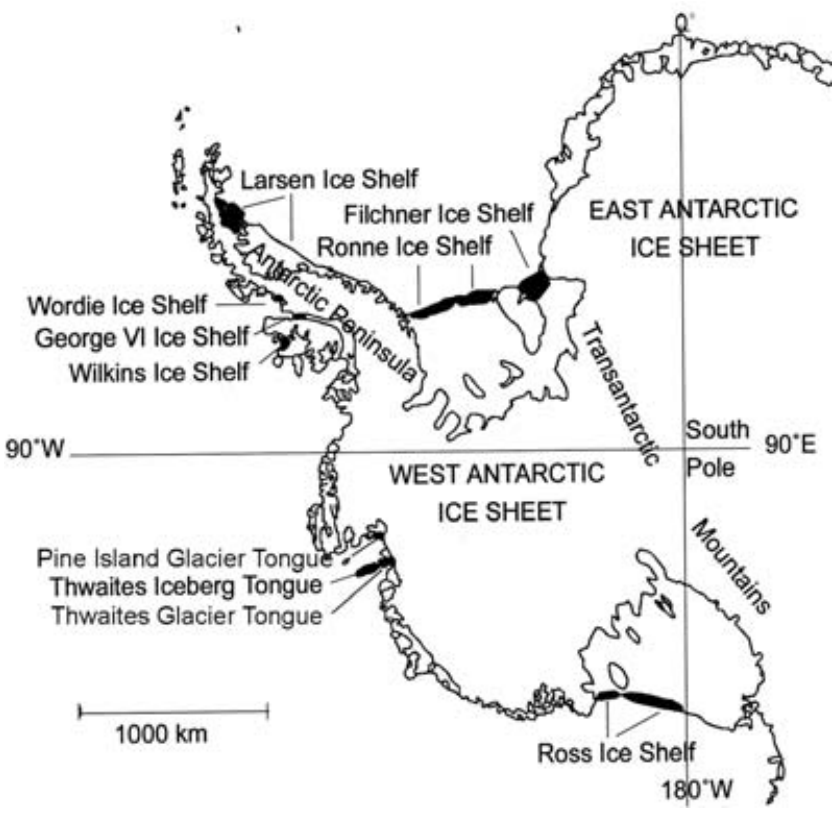

Fig. 1. Location map showing calved regions from ice shelves in West Antarctica since 1985. Black regions have calved. 
Glaciological studies of icebergs calving from ice shelves began with a theoretical investigation of the stress field at the calving front (Reeh 1968). Nye (1957), Smith (1976), and Weertman (1977) studied the depth and spacing of surface crevasses, including deeper penetration when water enters crevasses (Weertman 1973). Weertman (1980) then showed that water-filled bottom crevasses can fracture most of the thickness of ice shelves. Vaughan (1993) applied yielding criteria to surface strain rates and Van der Veen (1998a, 1998b) applied principles of fracture mechanics to these studies. Rist et al. (1999, 2002) introduced a new analysis of fracture mechanics and applied it to calculating the stress field on the Ronne Ice Shelf in Antarctica, using the finite-element model of ice-shelf dynamics developed by MacAyeal \& Thomas (1982). Published field data controlled the model, with experimental determinations of fracture toughness in ice determined by Rist et al. (1996), using techniques in rock mechanics. Satellite images of crevasse fields were used to compare with stress fields and crevasse patterns generated by the model. Most recently, MacAyeal et al. (2003) have presented a theory to show how closely spaced water-filled crevasses is leading to catastrophic disintegration of the Larsen Ice Shelf.

None of these studies addresses the problem of how giant icebergs are released from Antarctic ice shelves, yet they contain the essential elements for a solution to this problem. Simply stated, the problem consists in linking three types of crack propagation in ice. The first type is propagation of surface or basal crevasses that are transverse to ice flow near the calving front. These crevasses can be hundreds of kilometers long. They propagate laterally with little or no increase in depth, so the ice overburden pressure is not a critical variable in determining the speed or length of their propagation. The second type is propagation of surface or basal crevasses that are parallel to ice flow near the calving front. These crevasses typically open when the calving front extends beyond an embayment or basal pinning points that confined the ice shelf laterally, so it can spread by both longitudinal and transverse extension. Then longitudinal crevasses open at the calving front and migrate backward to intersect the long transverse crevasses. Alternatively, shear crevasses opening at 45 degrees to the calving front and to sidewalls of the ice-shelf embayment can rotate to a longitudinal orientation in simple shear and migrate back to intersect the long transverse crevasses. The third type of crevasse propagation is vertically downward from the top surface or vertically upward from the bottom surface. Downward propagation will encounter increasing pressure from the ice overburden, unless surface meltwater fills the top crevasses, whereas the ice overburden pressure is always exceeded by water pressure in bottom crevasses that propagate upward, until they reach sea level. Giant Antarctic icebergs calve when all three types of crevasse propagation intersect through the whole ice thickness. A first step toward the goal of treating all three types of crevasses holistically is taken here. Our approach combines earlier work for brittle and ductile fracture.

\section{Pioneering work in brittle fracture}

Griffith (1920, 1924) expanded upon previous work in elasticity by Inglis (1913) to determine the factors that control brittle fracture in solids. The initial step was a study of the stress field around an elliptical flaw contained within a solid, subjected to far-field stresses that acted perpendicular to the major axis of the ellipse. The ellipse corresponds to a transverse crevasse, and a half-ellipse corresponds to longitudinal crevasses extending to the calving front and to vertical propagation of both types of crevasses. The Inglis elastic fracture solution to this problem relates applied tensile stress $\sigma$ to yield stress $\sigma_{Y}$ of the material and geometric properties of the elliptical flaw.

The stress intensity approach pioneered by Irwin (1948) employs the normal and shear stresses at the tip of a crack in an infinite elastic solid being acted upon by a far field tensile stress $\sigma$. These stresses are derived in standard texts on fracture mechanics, such as Kanninen \& Popelar (1985), Broek (1978, 1988), and Lawn (1993). They are used to obtain a stress intensity factor $K$ for cracks opened in tension, shear, or torsion. The tension mode has been examined by glaciologists who study calving, for which $K=$ $K_{I}$. The condition for fracture is that $K_{I}$ must exceed some critical value $K_{I c}$, which is a material property called the fracture toughness.

Derivations of stress intensity factors can be found in Sih (1973a, 1973b), Tada et al. (1973), and Rooke \& Cartwright (1976). Solutions exist for single edge crevasses, equally spaced crevasses, crevasses filled with water, and crevasses through firn into ice (e.g. Weertman 1973, 1977, 1980, Smith 1976, Nemat-Nasser et al. 1979, Van der Veen 1996, 1997, 1998a, 1998b, Rist et al. 1996, 1999, 2002).

Crevasses filled with water lead to catastrophic disintegration of an ice shelf (Scambos et al. 2000, MacAyeal et al. 2003). The most obvious example of a water-filled crevasse is a basal crevasse in a floating ice shelf. Seawater fills the crevasse, allowing it to penetrate upward through most of the ice thickness and close to sea level (Weertman 1980, Van der Veen 1998b).

Linear elastic fracture mechanics employs an energy balance to obtain the rate of crack growth in terms of material properties and system variables. These results have application to iceberg calving. Griffith (1920) assumed cracks would grow when it was energetically favourable to do so, namely, the potential energy of the system would decrease. The total energy of the system is the sum of the potential energy of the load on the system, the elastic energy stored in the material (together this is the mechanical energy), and the work energy required to form new crack surfaces. A necessary and sufficient condition for a crack opening in simple tension is minimizing the total energy per 
unit area of the crack surfaces (Griffith 1920, 1924).

Mott (1948) assumed that since the total energy must be constant, its derivative with respect to crack length will be zero. From this assumption, Mott obtained the crack velocity through the material, which was near the speed of sound in the material. Roberts \& Wells (1954), Berry (1960), and Dulaney \& Brace (1960) found shortcomings in the pioneering formulation of Mott. Their work reduced the crack velocity to $38 \%$ of the sonic velocity for a Poisson's ratio of one-fourth.

These studies indicate that a crack will form in a solid in very little time. Consider this account from Swithinbank (1999, p. 96) reporting the formation of a new crevasse on an ice shelf in Antarctica: "As I was hammering in a tent peg, there was an alarming splitting sound that lasted seconds, rose in a crescendo, and ended with a crack like a rifle shot. I leapt away thinking that I had broken the snow bridge over a crevasse. I must have initiated a crack which then propagated because the surface was under tension. Next morning I found a 2 millimetre wide crack extending 35 metres from the tent peg that had given me a moment of terror."

Our contribution to crack propagation in ice shelves by brittle fracture is based on this observation by Swithinbank (Kenneally \& Hughes 2004).

\section{Pioneering work in ductile fracture}

There are limitations to the use of linear elastic fracture mechanics in describing actual processes. In particular, stress is infinite at the crack tip, whereas ductile deformation occurs at the crack tip and imposes a finite yield stress.

An alternate yet equivalent treatment of crack formation

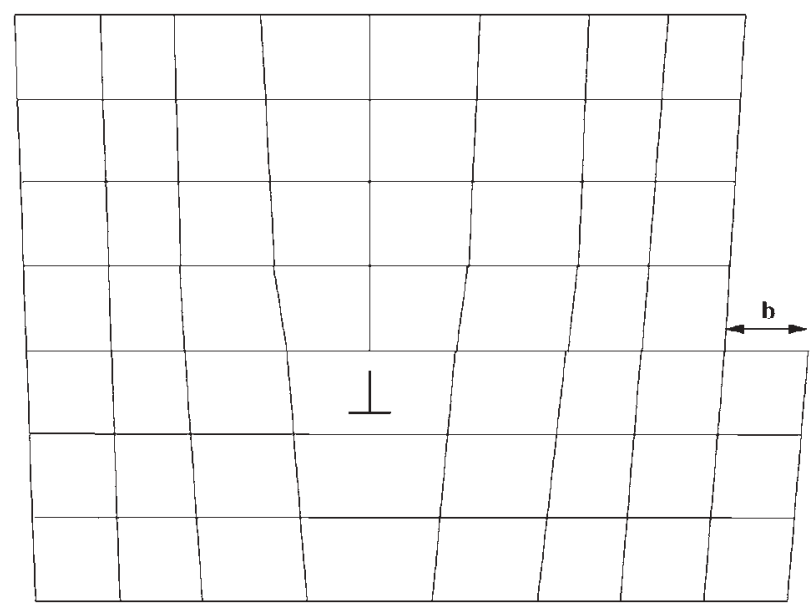

Fig. 2. Illustration of a dislocation and Burgers vector $\boldsymbol{b}$. The lattice is distorted the dislocation $\perp$, causing a displacement $\boldsymbol{b}$ to the right. Overall displacement $\boldsymbol{b}_{T}$ results from a number of individual dislocations. in a crystalline solid is based on dislocation theory, which makes use of the ductile zone. The problem is analysed by considering a build-up of dislocations in a system. Where fracture mechanics considers that the stresses at a crack tip become infinite, dislocation theory treats the infinite stress build-up as a collection of discrete dislocations at the crack tip and along the crack surface. When used in conjunction with linear elastic fracture mechanics, where the depths of crevasses in ice were determined, a more complete picture of crevasse formation is obtained. The results show that newly formed crevasses in ice are actually quite benign, and dangerous crevasse fields appear only after ductile deformation of the ice due to creep processes. Since ductile fracture by dislocations is rather new to studying calving of icebergs, the basic approach will now be reviewed and then extended.

The Burgers vector defines a dislocation mathematically, when an edge dislocation distorts a crystalline solid, as illustrated in Fig. 2. This is consistent with the GriffithInglis crack. When a large number of dislocations are present within a solid, the collection of Burgers vectors can be represented by a distribution function $B\left(x_{i}\right)$ where $x_{i}$ can be either $x, y$, or $z$. The total Burgers vector of dislocations located between $x_{i}$ and $x_{i}+\delta x_{i}$ is $B\left(x_{i}\right) \delta x_{i}$. The total displacement across a crack plane when dislocations pile up at $x_{i}$ can then be written as:

$$
D\left(x_{i}\right)=\int_{x_{i}}^{\infty} B\left(x_{i}^{\prime}\right) d x_{i}^{\prime}
$$

since the net displacement is the total Burgers vector. The traction stress at $x_{i}$ produced on the plane of a discrete dislocation Burgers vector located at $X_{i}^{\prime}$ is (Weertman 1996):

$$
\sigma_{T}\left(x_{i}\right)=\frac{G b}{2 \pi \alpha_{j}\left(x_{i}-x_{i}^{\prime}\right)}
$$

where $G$ is the shear modulus and $\alpha_{j}$ is dependent on the type of dislocation being considered $(j=e$ for edge dislocations and $j=s$ for screw dislocations). If the total distribution of the Burgers vector can be written as $B\left(x_{i}\right)$ as defined earlier, then the stress is:

$$
\sigma_{T}\left(x_{i}\right)=\frac{G}{2 \pi \alpha_{j}} \int_{-\infty}^{\infty} \frac{B\left(x_{i}^{\prime}\right) d x_{i}^{\prime}}{x_{i}-x_{i}^{\prime}} .
$$

The inverse of Eq. (3) is:

$$
B\left(x_{i}\right)=-\frac{2 \alpha_{j}}{\pi G} \int_{-\infty}^{\infty} \frac{\sigma\left(x_{i}^{\prime}\right) d x_{i}^{\prime}}{x_{i}-x_{i}^{\prime}} .
$$

Equations (3) \& (4) are Hilbert transforms of one another. An explicit form for the dislocation distribution given in the pioneering work by Muskhelishvili (1953) is:

$$
B\left(x_{i}\right)=-\frac{2 \alpha_{j} \sqrt{c^{2}-x_{i}^{2}}}{\pi G} \int_{-c}^{c} \frac{\sigma\left(x_{i}^{\prime}\right) d x_{i}^{\prime}}{\left(x_{i}-x_{i}^{\prime}\right) \sqrt{c^{2}-x_{i}^{\prime 2}}}
$$


where the distribution is defined to exist between the points $-c<x_{i}<c$ and is zero at all other points. The stress in regions where $\left|x_{i}\right|>c$ is given as:

$$
\sigma\left(x_{i}\right)=-\frac{\sqrt{x_{i}^{2}-c^{2}}}{\pi} \frac{x_{i}}{\left|x_{i}\right|} \int_{-c}^{c} \frac{\sigma\left(x_{i}^{\prime}\right) d x_{i}^{\prime}}{\left(x_{i}-x_{i}^{\prime}\right) \sqrt{c^{2}-x_{i}^{\prime 2}}} .
$$

With these expressions, the dislocation density and stress are known everywhere along the crack plane. The term $c$ must satisfy the following relations (Weertman 1996):

$$
\begin{gathered}
\int_{-c}^{c} \frac{\sigma\left(\mathrm{x}_{\mathrm{i}}\right) \mathrm{dx}_{\mathrm{i}}}{\sqrt{\mathrm{c}^{2}-\mathrm{x}_{\mathrm{i}}^{2}}}=0 \\
\int_{-c}^{c} \frac{x_{i} \sigma\left(\mathrm{x}_{\mathrm{i}}\right) \mathrm{dx}_{\mathrm{i}}}{\sqrt{\mathrm{c}^{2}-\mathrm{x}_{\mathrm{i}}^{2}}}=\frac{G b_{T}}{2 \alpha_{j}} \\
\int_{-c}^{c} \frac{\left|x_{i}\right| \sigma\left(\mathrm{x}_{\mathrm{i}}\right) \mathrm{dx}}{\sqrt{\mathrm{c}^{2}-\mathrm{x}_{\mathrm{i}}^{2}}}=\frac{G\left(b_{R}-b_{L}\right)}{2 \alpha_{j}} .
\end{gathered}
$$

In these relations, $\boldsymbol{b}_{T}=\boldsymbol{b}_{R}+\boldsymbol{b}_{L}$ is the net Burgers vector of all dislocations, $\boldsymbol{b}_{R}$ is the net Burgers vector in the region $0<x_{i}<\infty$ and $\boldsymbol{b}_{L}$ is the net Burgers vector in the region $-\infty<x_{i}<0$.

Explicit forms for the solutions to Eqs (5) \& (6) are given in pioneering work by Weertman (1996) for the case of an infinite stress at the crack tip. Using his convention, the following relations for "mean stress" from $+a$ to $-a$ in the crack plane are defined for notational convenience (in the limit $c \rightarrow a$, the crack length):

$$
\begin{gathered}
\bar{\sigma}_{A}=-\frac{1}{\pi} \int_{-a}^{a} \frac{\sigma\left(x_{i}\right) d x_{i}}{\sqrt{a^{2}-x_{i}^{2}}} \\
\bar{\sigma}_{B}=-\frac{1}{\pi a} \int_{-a}^{a} \frac{x_{i} \sigma\left(x_{i}\right) d x_{i}}{\sqrt{a^{2}-x_{i}^{2}}} .
\end{gathered}
$$

With these definitions, Eqs (5) \& (6) can be written as:

$$
\begin{gathered}
B\left(x_{i}\right)=-\frac{2 \alpha_{j} \sqrt{a^{2}-x_{i}^{2}}}{\pi G} \int_{-a}^{a} \frac{\sigma\left(x_{i}^{\prime}\right) d x_{i}^{\prime}}{\left(x_{i}-x_{i}^{\prime}\right) \sqrt{a^{2}-x_{i}^{\prime 2}}} \\
+\frac{2 \alpha_{j}}{G}\left[\bar{\sigma}_{A} \frac{x_{i}}{\sqrt{a^{2}-x_{i}^{2}}}+\left(\bar{\sigma}_{B}+\frac{G b_{T}}{2 \alpha_{j} \pi a}\right) \frac{a}{\sqrt{a^{2}-x_{i}^{2}}}\right]
\end{gathered}
$$

and

$$
\begin{aligned}
& \sigma\left(x_{i}\right)=\frac{\sqrt{a^{2}-x_{i}^{2}}}{\pi} \frac{x_{i}}{\left|x_{i}\right|} \int_{-a}^{a} \frac{\sigma\left(x_{i}^{\prime}\right) d x_{i}^{\prime}}{\left(x_{i}-x_{i}^{\prime}\right) \sqrt{a^{2}-x_{i}^{2}}} \\
& +\frac{x_{i}}{\left|x_{i}\right|}\left[\bar{\sigma}_{A} \frac{x_{i}}{\sqrt{a^{2}-x_{i}^{2}}}-\bar{\sigma}_{A}+\left(\bar{\sigma}_{B}+\frac{G b_{T}}{2 \alpha_{j} \pi a}\right) \frac{a}{\sqrt{a^{2}-x_{i}^{2}}}\right] .
\end{aligned}
$$

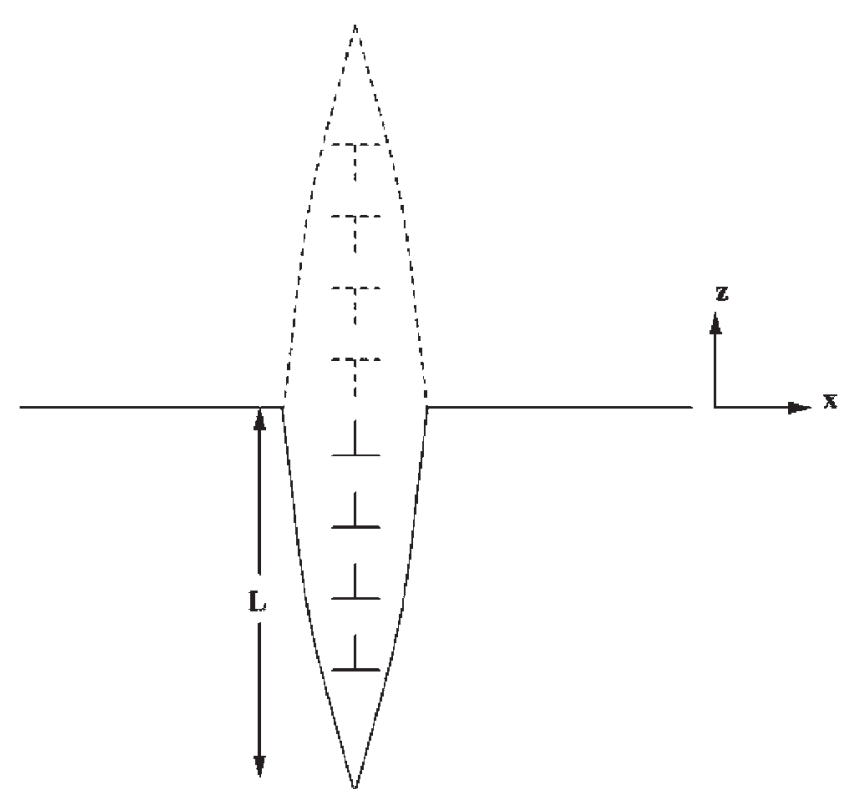

Fig. 3. Illustration of an image crevasse situated directly above a real crevasse of depth $L$. The image crevasse also contains image dislocations, which are equal in number and opposite in orientation to the real dislocations, $\perp$. In the map plane, $L$ is the length of a longitudinal crevasse and $2 L$ is the length of a transverse crevasse.

Using the relation given by Eq. (1), the displacement can be solved as a function of depth into the material (or length in the map plane) up to a maximum dictated by the overall depth (or length) of the crevasse. All that remains is to determine the functional forms for Eq. (8) and plug these into Eq. (9) so that the integral in Eq. (1) can be evaluated.

As illustrated in Fig. 3, Weertman (1996) defines an "image" crack of height $L$ located exactly above a real crack penetrating a depth $L$ into the ice. The "image" crack is also real for transverse crevasses. The real and imaginary crevasses are then subjected to an applied stress:

$$
\sigma_{\text {app }}(z)=\sigma-\rho_{i} g|z|
$$

where $\sigma$ is the deviatoric tensile pulling stress in the glacier and $\rho_{i} g|z|$ represents the ice overburden pressure, taken as linearly increasing with depth, which will be amended later to take into account variations of the ice density with depth. The absolute value of $z$ is necessary to insure proper symmetry. This applied stress is inserted into Eq. (9) with a change of variables appropriate to a more intuitive coordinate system, i.e. vertical direction $z$ in the direction of crack growth:

$$
\begin{aligned}
B_{x}(z)=-\frac{2 \alpha}{G} & \frac{\bar{\sigma}_{A} z}{\sqrt{L^{2}-z^{2}}}-\frac{2 \alpha}{G} \frac{\bar{\sigma}_{B} L}{\sqrt{L^{2}-z^{2}}}-\frac{b_{\Gamma} L}{\pi \sqrt{L^{2}-z^{2}}} \\
& +\frac{2 \alpha \sqrt{L^{2}-z^{2}}}{\pi G} \int_{-L}^{L} \frac{\sigma\left(z^{\prime}\right) d z^{\prime}}{\left(z-z^{\prime}\right) \sqrt{L^{2}-z^{\prime 2}}} .
\end{aligned}
$$


In this expression, $\sigma\left(z^{\prime}\right)=-\sigma_{\text {app }}\left(z^{\prime}\right)$, the net Burgers vector $\boldsymbol{b}_{T}=0$ (the image crevasse cancels all contributions from the real crevasse), $\sigma_{\dot{j}}=\sigma_{e}=1-v$ for edge dislocations illustrated in Fig. 2 (where $v$ is Poisson's ratio) $\bar{\sigma}_{A}$ and $\bar{\sigma}_{B}$ are

$$
\begin{gathered}
\bar{\sigma}_{A}=-\frac{1}{\pi} \int_{-L}^{L} \frac{\sigma(z) d z}{\sqrt{L^{2}-z^{2}}} \\
\bar{\sigma}_{B}=-\frac{1}{\pi L} \int_{-L}^{L} \frac{z \sigma(z) d z}{\sqrt{L^{2}-z^{2}}}
\end{gathered}
$$

The dislocation distribution is obtained by inserting Eq. (11) into Eq. (12) and the displacement of the crevasse is found by then inserting $B_{x}(z)$ into Eq. (1) and integrating.

The dislocation distribution is found to be:

$$
B_{x}(z)=-\frac{2 \alpha}{G} \bar{\sigma}_{A} \frac{z}{\sqrt{L^{2}-z^{2}}}-\frac{2 \alpha \rho_{i} g z}{\pi G} \ln \left(\frac{L+\sqrt{L^{2}-z^{2}}}{L-\sqrt{L^{2}-z^{2}}}\right) \text {. }
$$

The displacement is then:

$$
\begin{aligned}
& D_{x}(z)=\int_{z}^{L} B_{x}\left(z^{\prime}\right) d z^{\prime}=-\frac{2 \alpha}{G} \bar{\sigma}_{A} \sqrt{L^{2}-z^{2}} \\
& +\frac{2 \alpha \rho_{i} g z}{\pi G} L \sqrt{L^{2}-z^{2}}-\frac{2 \alpha \rho_{i} g z^{2}}{\pi G} \ln \left(\frac{L+\sqrt{L^{2}-z^{2}}}{L-\sqrt{L^{2}-z^{2}}}\right)
\end{aligned}
$$

where $\bar{\sigma}_{A}=\sigma-2 \rho_{i} g L / \pi$ and $\bar{\sigma}_{B}=0$.

In this constant density model, the total depth to which the crevasse penetrates is found by solving for $L$ in the relation given by Eq. (13a):

$$
L=\frac{\pi\left(\sigma-\bar{\sigma}_{A}\right)}{2 \rho_{i} g} .
$$

The typical value for the tensile stress $\sigma 1$ bar $(0.1 \mathrm{MPa})$ is used and the density of ice is $\rho_{I}=917 \mathrm{~kg} \mathrm{~m}^{-3}$. A value of 0.3 is taken for Poisson's ratio $v$ and the shear modulus $G$ is 3.6 GPa (Simmons \& Wang 1971). The stress intensity factor (SIF) at the tip of the crevasse is $K_{I}=\bar{\sigma}_{A} \sqrt{\pi L}$, the SIF for the simple case of a crack with length $2 \mathrm{~L}$ contained in a solid. Writing this relation in terms of the critical stress intensity factor $K_{c}$ (taken here as $0.1 \mathrm{MPa} \cdot \mathrm{m}^{1 / 2}$ ) and inserting it into Eq. (16) yields a value $L \approx 15 \mathrm{~m}$. When this total depth is inserted into Eq. (15) this yields a maximum opening width $D_{x}(0)$ of only $0.33 \mathrm{~mm}$ !

Weertman (1996) used a constant ice density in his calculation of the stress acting on a crevasse. For most glaciological applications Eq. (17) shows how density increases with depth, with constant $C$ determined by field observation for densities $\rho_{i}$ and $\rho_{S}$ of ice and surface snow, respectively (Paterson 1994).

$$
\rho(z)=\rho_{i}-\left(\rho_{i}-\rho_{s}\right) e^{-C z}
$$

The applied stress at a depth $z$ will now be (with absolute values still required to preserve symmetry between the real and imaginary crevasse):

$$
\sigma(z)=-\sigma_{a p p}=-\sigma+\rho_{i} g|z|-\frac{\left(\rho_{i}-\rho_{s}\right) g}{C}\left(1-e^{-C|z|}\right) .
$$

This new stress needs to be inserted into the relations given by Eqs (8) \& (9), which can then be integrated to yield a new displacement function $D_{x}(z)$.

By inspection it can be seen Eq. (8b) will be zero, since the integration is done for an odd function over a symmetric range. The mean stress $\bar{\sigma}_{A}$ still needs to be calculated. Integration of the first two terms on the right hand side of Eq. (18) is trivial, but the third term presents more difficulty. In its current form, the integral:

$$
I=\int_{-L}^{L} \frac{e^{-C\left|z^{\prime}\right|} d z^{\prime}}{\sqrt{L^{2}-z^{\prime 2}}}
$$

cannot be analytically determined. However, maximum penetration depths of crevasses are on the order of tens of metres and $C$ is on the order of 0.02 . This means the argument of the exponential will be on the order of 0.2 , which is small enough that a series expansion of few terms is a valid approximation:

$$
e^{-C|z|}=\sum_{n=0}^{\infty}(-1)^{n} \frac{(C|z|)^{n}}{n !} \approx 1-C|z|+\frac{C^{2}}{2}|z|^{2}
$$

with all terms greater than $O\left(z^{2}\right)$ ignored. The explicit form for the mean stress $\bar{\sigma}_{A}$ is then:

$$
\bar{\sigma}_{A} \approx \sigma-\frac{2 \rho_{i} g L}{\pi}+\frac{\left(\rho_{i}-\rho_{s}\right) g}{\pi}\left(2 L-\frac{\pi C L^{2}}{4}\right) .
$$

The new stress Eq. (18) is inserted into Eq. (9) to yield:

$$
\begin{array}{r}
B_{x}(z)=-\frac{2 \alpha}{G} \bar{\sigma}_{A} \frac{z}{\sqrt{L^{2}-z^{2}}}-\frac{2 \alpha \rho_{s} g}{\pi G} z \ln \left(\frac{L+\sqrt{L^{2}-z^{2}}}{L-\sqrt{L^{2}-z^{2}}}\right) \\
-\frac{\alpha\left(\rho_{i}-\rho_{s}\right) g C}{G} z \sqrt{L^{2}-z^{2}} .
\end{array}
$$

The first two terms on the right hand side of Eq. (22) are the same as the terms in the Weertman constant density model distribution, Eq. (14), with the only difference being $\rho_{i} \rightarrow \rho_{s}$ in the second term. The last term is a correction to take into account the variation of density with depth. Finally, to get the lateral width of the crevasse as a function of depth $z$, Eq. (1) is utilized, with $z$ replacing $x$ :

$$
D_{x}(z)=\int_{L}^{z} B_{x}\left(z^{\prime}\right) d z^{\prime} .
$$

The final form for $D_{x}(z)$ is: 


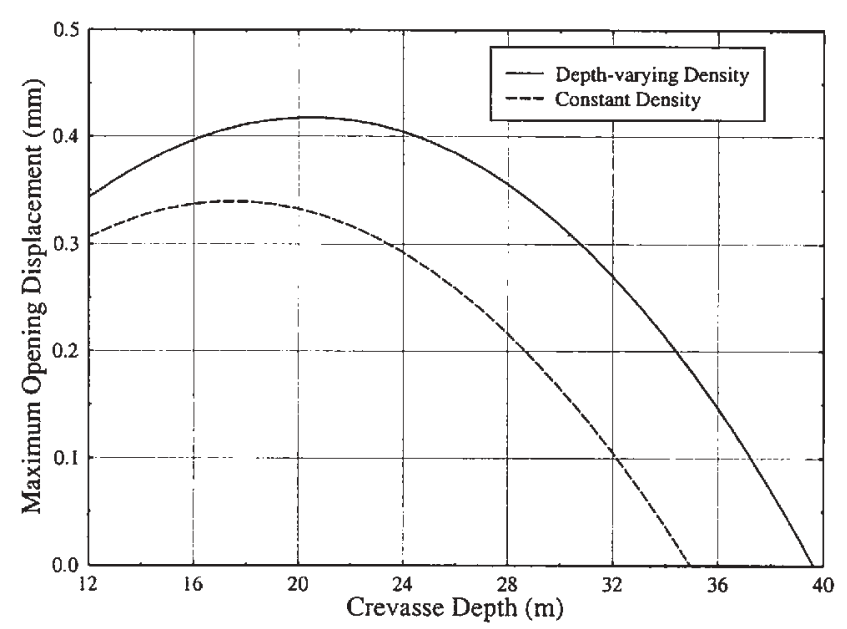

Fig. 4. Comparison of the two solutions describing maximum crevasse opening displacement with crevasse depth.

$$
\begin{aligned}
D_{x}(z)= & -\frac{2 \alpha}{G} \bar{\sigma}_{A} \sqrt{L^{2}-z^{2}}+\frac{\alpha\left(\rho_{i}-\rho_{s}\right) g C}{3 G} \sqrt{\left(L^{2}-z^{2}\right)^{3}} \\
& +\frac{2 \alpha \rho_{s} g}{\pi G}\left[\sqrt{L^{2}-z^{2}}-\frac{z^{2}}{2} \ln \left(\frac{L+\sqrt{L^{2}-z^{2}}}{L-\sqrt{L^{2}-z^{2}}}\right)\right]
\end{aligned}
$$

which will be considered a valid approximation for crevasse depths $L \leq 35 \mathrm{~m}$. The maximum depth $L$ is taken from earlier calculations in linear elastic fracture mechanics. Again, the maximum width of the crevasse $D_{x, \max }=D_{x}(0)$ is quite small; a crevasse of depth $25 \mathrm{~m}$ only opens to $0.38 \mathrm{~mm}$ at the surface (Kenneally \& Hughes 2004). The relationship between the maximum crevasse opening at the surface and the depth of the crevasse is shown in Fig. 4 for the cases of constant and increasing density with depth. The width of the crevasse measured by Swithinbank (1999), soon after he caused its formation, was on the order of $2 \mathrm{~mm}$. The model derived in this section using dislocation theory may have shortcomings but it seems to be validated by Swithinbank's field evidence.

\section{Combining brittle and ductile fracture}

Denoting the stress perpendicular, or normal, to the cracking plane with the subscript $N$ allows us to write for ice, following Barnby \& Nicholson (1977):

$$
\sigma_{N}=\frac{K_{I}}{\sqrt{2 \pi z}}
$$

where $K_{I}$ is the stress intensity factor for a tensile crack and $\sigma_{N}$ is considered to be transient at a fixed total strain.

Steady-state values of the stress were determined by Barnby \& Nicholson (1977) to be inversely proportional to z, specifically:

$$
\sigma_{s s} \propto Z^{-1 /(n+1)}
$$

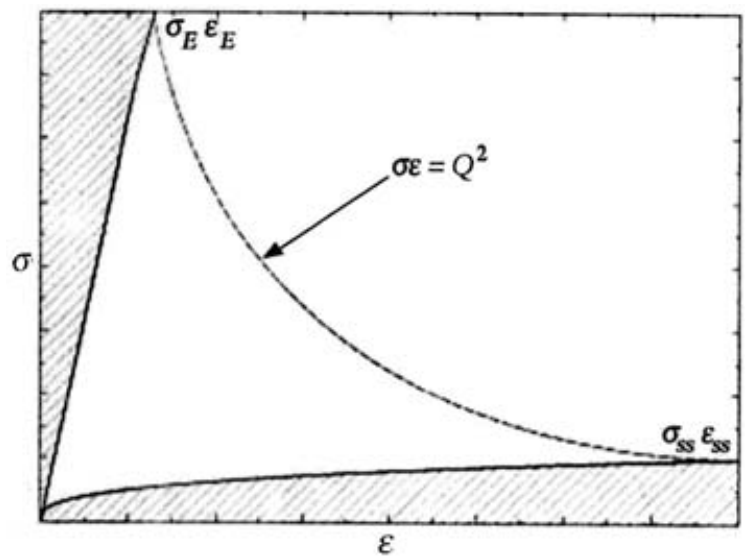

Fig. 5. Illustration of the relaxation relation. The elastic stressstrain curve (straight solid line) and the strain hardening stressstrain curve (curved solid line) satisfy points on the hyperbola (dashed line) defined by the strain energy relation in Eq. (29). The hyperbolic $\sigma \varepsilon$ curve intersects the elastic $\sigma_{E}, \varepsilon_{E}$ and strain hardening $\sigma_{s s}, \varepsilon_{s s}$ curve, when the elastic and ductile strain energies (shaded areas) are equal, see Eq. (30).

where $n$ in our application is the exponent in the flow law for creep of ice (Glen 1955):

$$
\dot{\varepsilon}=A \sigma^{n} \text {. }
$$

When the flow law is written in integrated form, strain rate $\dot{\varepsilon}$ produces strain $\varepsilon$ in time $t$ and softness constant $A$ becomes a time-dependent hardening variable $A^{\prime}=A t^{m}$, where $m=1 / 3$ for transient creep and $m=1$ for steady-state creep. Then Eq. (27) can be written as a strain hardening law, with strain hardening taking place mainly during transient creep:

$$
\varepsilon=A^{\prime} \sigma^{n}
$$

The relationship between $n$ for creep and $n$ for strain hardening is discussed by Hughes (1998, pp. 119-138 \& 196-200). Both processes have comparable values of $n$ during transient creep and unstable steady-state creep just prior to recrystallization in ice.

Thus far, the analysis has dealt with the creep-induced stresses in the material. To connect the steady-state ductile solution with the elastic solution, it is assumed that the stress at all points ahead of the crack tip relax in a ductile manner from the elastic solution via the relation (Barnby \& Nicholson 1977):

$$
\sigma \varepsilon=Q^{2}
$$

where $\sigma \varepsilon$ is the strain energy and $Q$ is some constant, see Fig. 5. This assumption results in a mathematical connection between the elastic stress-strain curve and the steady-state ductile curve:

$$
\sigma_{E} \varepsilon_{E}=\sigma_{s s} \varepsilon_{s s}
$$

where the subscript $\mathrm{E}$ denotes the elastic situation. The 


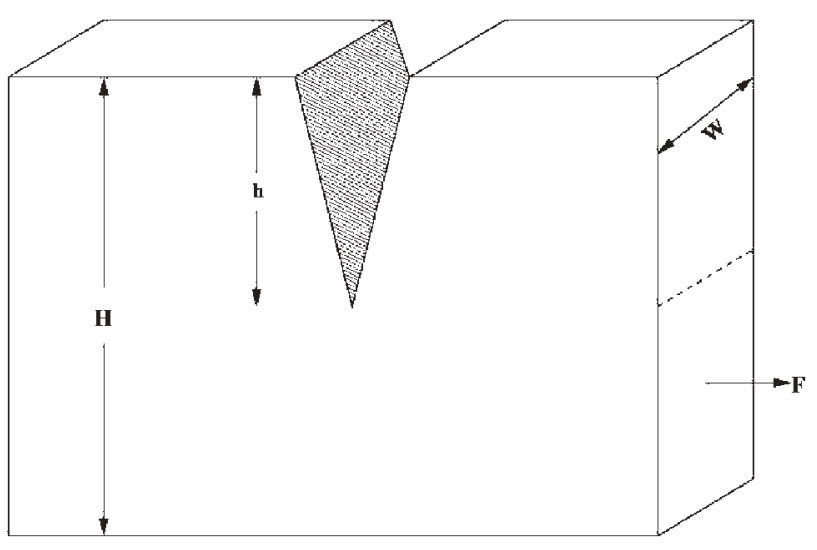

Fig. 6. Geometry of the system for Eq. (36).

elastic stress is given by Eq. (25). Recasting the form of Eq. (28) as $\varepsilon_{s s}=A^{\prime} \sigma_{s s}^{n}$, the integrated form of the flow law for ice with the time dependence contained in the variable A', and employing Eq. (30) gives:

$$
\sigma_{s s}=\frac{\sigma_{E} \varepsilon_{E}}{\varepsilon_{s s}}=\frac{\sigma_{E} \varepsilon_{E}}{A^{\prime} \sigma_{s s}^{n}}
$$

Since $\sigma_{E}=E \varepsilon_{E}$ for elastic Young's modulus $E$ (Hooke's Law):

$$
\sigma_{s s}^{n+1}=\frac{\sigma_{E}^{2}}{A^{\prime} E} .
$$

Substituting the elastic normal stress from Eq. (25) gives:

$$
\sigma_{s s}^{n+1}=\frac{K_{I}^{2}}{2 \pi z A^{\prime} E}
$$

which is the final form given by Barnby \& Nicholson (1977):

$$
\sigma_{s s}=\left[\frac{K_{I}^{2}}{2 \pi A^{\prime} E}\right]^{1 /(n+1)} z^{-1 /(n+1)}
$$

This result gives the steady state distribution of the stresses ahead of a crack tip. It displays the correct dependence on $z$ shown in Eq. (26) and it includes parameters for both elastic $(E, K)$ and ductile $\left(A^{\prime}, n\right)$, material properties (Hutchinson 1968, Rice \& Rosengren 1968, Barnby \& Nicholson 1977).

\section{A new crack growth law}

The original treatment of crack growth was by Barnby \& Nicholson (1977) with a correction and modification by Evans (1984). Consider the HRR (Hutchinson, Rice, and Rosengren) stress fields of a strain hardening ductile material (Hutchinson 1968, Rice \& Rosengren 1968). The results derived in these papers give the normal stress fields, normal in relation to the plane along which the crack is propagating, as :

$$
\sigma_{N}=C^{*} r^{-1 /(n+1)}
$$

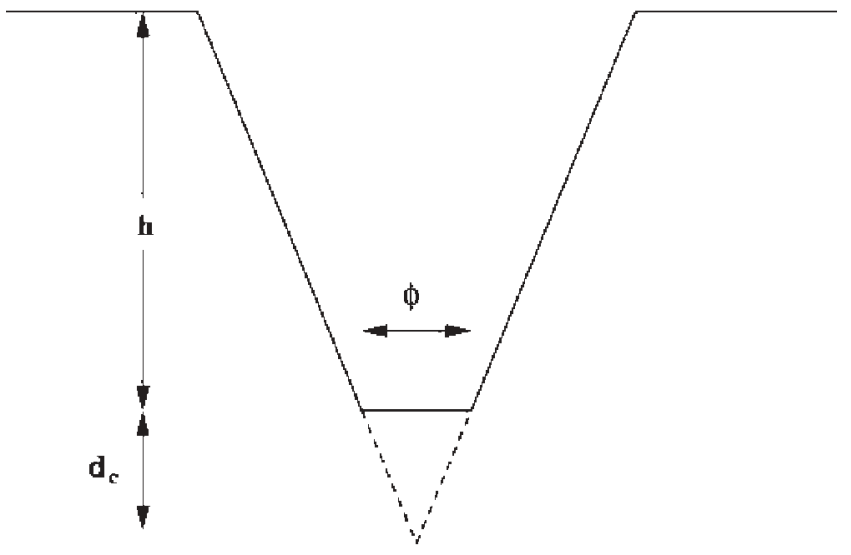

Fig. 7. Blunted crack tip and variables to describe the geometry as defined by Evans (1984).

where $C^{*}$ is related to the energies contained in the stress fields. For a pre-existing crack of depth $h$ in a solid of thickness $H$, width $W$, and infinite length, as shown in Fig. 6, the net load $F$ that acts on the uncracked portion of the solid can be written as:

$$
F=W \int_{0}^{H-h} \sigma_{N}(r) d r
$$

where the normal stress $\sigma_{N}(r)$ is taken to be Eq. (34). Substituting and carrying out the integration with $r \rightarrow z$, the force is:

$$
F=W\left(\frac{K^{2}}{2 \pi A^{\prime} E}\right)^{1 /(n+1)}\left(\frac{n+1}{n}\right)(H-h)^{n /(n+1)}
$$

From Eq. (34) with $\sigma_{\mathrm{ss}}=\sigma_{\mathrm{n}}$, Eq. (37) becomes:

$$
\sigma_{N}=\frac{F}{W} z^{-1 /(n+1)}\left(\frac{n}{n+1}\right)(H-h)^{-n /(n+1)} .
$$

The net stress on the uncracked portion is force $F$ acting on uncracked area $(H-h) W$ :

$$
\sigma_{\text {net }}=\frac{F}{(H-h) W} \text {. }
$$

Combining Eqs (38) \& (39) gives:

$$
\sigma_{N}=\frac{n}{n+1} \sigma_{n e t}\left(\frac{Z}{H-h}\right)^{-1 /(n+1)}
$$

which relates the normal stress field ahead of the crack tip to geometric properties of the system and the strain hardening exponent. These are readily available.

For practical applications of this formula, consider the case of a single "blunted" edge crack in the solid (Evans 1984). A blunted crack is defined as a crack where the two faces do not meet in a sharp point; rather, they are joined by a ligament of some length (Fig. 7). This allows an explicit form for the crack growth rate to be determined. If the length of the ligament is $\phi$, and the critical ligament length is given by: 


$$
\phi_{c}=\varepsilon_{f} \phi
$$

where $\varepsilon_{f}$ is the failure strain of the ligament, one can differentiate and determine the critical ligament displacement rate to be:

$$
\dot{\phi}_{c}=\left(\dot{\varepsilon}_{n} \phi\right)_{z=d_{c}}
$$

where the variable $d_{c}$ is the distance from the blunted end of the crack tip to the point where the two faces would normally intersect as a sharp edge. The flow law for creep given by Eq. (27), with $\sigma=\sigma_{N}$ given by Eq. (40) when $z=$ $d_{c}$, can be substituted into Eq. (42) to get:

$$
\dot{\phi}_{c}=\phi A\left[\frac{n}{n+1} \sigma_{n e t}\left(\frac{d_{c}}{H-h}\right)^{-1 /(n+1)}\right]^{n} .
$$

The variable $d_{c}$ is a controlling quantity that determines exactly how far the crack will grow in each time increment. Assume that the crack will propagate forward a distance $d_{c}$ when the stretched length of the ligament acquires the critical value $\phi_{c}$. The crack is not only getting longer, but also wider. With this assumption a rate of crack growth can then be defined, using similar triangles, as:

$$
\frac{\dot{h}}{\dot{\phi}_{c}}=\frac{d_{c}}{\phi_{c}} \text {. }
$$

Recognizing that:

$$
\varepsilon_{f}=\frac{\phi_{c}}{\phi}
$$

and substituting Eqs (44) \& (45) into Eq. (43), the final crack growth rate law is determined to be:

$$
\dot{h}=\frac{A}{\varepsilon_{f}}\left[\frac{n \sigma_{n e t}}{n+1}\right]^{n}(H-h)^{n /(n+1)} d_{c}^{1 /(n+1)} .
$$

An explicit form for crack length as a function of time can now be obtained. Rewrite Eq. (46) in the form:

$$
\dot{h}=k(H-h)^{n /(n+1)}
$$

where the variable $k$ has been introduced as:

$$
k=\frac{A}{\varepsilon_{f}}\left(\frac{n \sigma_{n e t}}{n+1}\right)^{n} d_{c}^{1 /(n+1)} .
$$

Integrating both sides with explicit limits:

$$
\int_{h_{o}}^{h} \frac{d h}{(H-h)^{n /(n+1)}}=\int_{0}^{t} k d t^{\prime}
$$

gives the analytical solution:

$$
h(t)=H-\left[\left(H-h_{o}\right)^{1 /(n+1)}-(n+1) k t\right]^{n+1} .
$$

Equation (50) is valuable if only for its simplicity, considering the analysis that was employed.

\section{Applications to ice shelves}

The longitudinal thickness profiles determined by Van der Veen (1999) for ice shelves can be related to distance $\mathrm{x}$ from the ice-shelf grounding line, where top and bottom crevasses can be nucleated when ice velocity increases as grounded ie becomes afloat. The simplest expression for ice velocity $U(x)$ at time $t$, where $t=0$ at $x=0$, is:

$$
x=U(x) t
$$

where mass-balance equilibrium requires that for $U_{0}$ and $H_{0}$ at $x=0$ :

$$
U(x) H(x)=U_{o} H_{o}+M x .
$$

Here a constant mass balance $M$ is positive for accumulation and negative for ablation. Combining Eqs (51) \& (52):

$$
x=\left[\frac{U_{o} H_{o}+M x}{H(x)}\right] t .
$$

Equation (50) is modelled for a linear ice shelf of length $L$. A basal crack of length $l$ starts with length $l_{0}$ at the grounding line, where $\delta U / \delta x$ is greatest, at time $t=0$. The crack will grow in the vertical direction as it propagates horizontally with velocity $U(x)$, the velocity of the ice shelf. Parameters to be used in the model include grounding-line values of thickness $H_{o}=1000 \mathrm{~m}$ and velocity $U_{o}=250 \mathrm{~m}$ $\mathrm{yr}^{-1}$. The ice softness parameter $A$ for $n=3$ is taken to be 6.8 x $10^{-24} \mathrm{~Pa}^{-3} \mathrm{~s}^{-1}$ for $T=0^{\circ} \mathrm{C}$ in water-filled crevasses (Paterson 1994). A failure strain $\varepsilon_{f}=0.4$, the recrystallization strain of ice, is chosen (Hughes 1998). Assume for simplicity that a surface crevasse of depth $a$ forms directly above the basal crevasse and is filled with meltwater deep enough to eliminate hydrostatic pressure from the solution. From fracture mechanics arguments, the initial length of the basal crack is taken to be $21 \mathrm{~m}$ and the depth of the surface crevasse is $32 \mathrm{~m}$. The difference arises from using a lower value for the fracture toughness of ice at the surface versus the base, see Rist et al. $(1996,1999)$. A quantity $\delta H$ is defined to be $\delta H=H-l(t)-a$ and that time $t_{\text {meet }}$ is achieved when $\delta H=0$.

The longitudinal tensile stress caused by gravitational spreading of an ice shelf is (Thomas 1973a, 1973b):

$$
\sigma_{T}=\sigma_{x}-\sigma_{z}=\frac{\rho_{i} g H(x)}{2\left(2+\dot{\varepsilon}_{y} / \dot{\varepsilon}_{x}\right)}\left(1-\frac{\rho_{i}}{\rho_{w}}\right)-\sigma_{c}
$$

where $\dot{\varepsilon}_{x}$ and $\dot{\varepsilon}_{y}$ are respective longitudinal and transverse strainrates and $\sigma_{c}$ is a compressive back-stress caused by side shear in an ice shelf confined in an embayment. If the sides are parallel, $\dot{\varepsilon}_{y}=0$ and $\sigma_{c}$ is given by the force balance for an ice shelf of length $L$ from the grounding line to the calving front:

$$
\sigma_{c} H(x) W=2 \bar{\sigma}_{x y} \bar{H}(x)(L-x)
$$

for ice-shelf thickness $H$ and width $W$ at distance $L-x$ from 
Table I. Summary of results for three different ice sheet profiles and a range of values $d_{c}$.

\begin{tabular}{lccc}
\hline $\begin{array}{l}\mathrm{d}_{\mathrm{c}} \\
(\mathrm{m})\end{array}$ & $\begin{array}{c}\mathrm{M} \\
\left(\mathrm{m} \mathrm{yr}^{-1}\right)\end{array}$ & $\begin{array}{c}\mathrm{t}_{\text {meet }} \\
(\mathrm{yrs})\end{array}$ & $\begin{array}{c}\mathrm{L}_{\text {meet }} \\
(\mathrm{km})\end{array}$ \\
\hline \multirow{3}{*}{0.1} & 0 & 47.6 & 11.9 \\
& 1 & 48.2 & 12.0 \\
& -1 & 46.5 & 11.6 \\
1 & 0 & 29.1 & 7.3 \\
& 1 & 29.2 & 7.3 \\
& -1 & 28.6 & 7.2 \\
5 & 0 & 20.1 & 5.1 \\
& 1 & 20.6 & 5.1 \\
\hline
\end{tabular}

the calving front, over which distance $\bar{H}$ is the average ice thickness and $\bar{\sigma}_{x y}$ is the average side shear stress. This was treated by Kenneally \& Hughes (2004), and is not revisited here. Equation (55) shows that maximum $\sigma_{c}$ is at the grounding line $(x=0)$ and zero at the calving front $(x=L)$. Values of $\sigma_{c}$ for the Ross Ice Shelf were determined by Thomas \& MacAyeal (1982).

Ice-shelf profiles derived by Van der Veen (1999) for three mass balances, $M=0, M=1 \mathrm{~m} \mathrm{a}^{-1}$, and $M=-1 \mathrm{~m} \mathrm{yr}^{-1}$, and $\sigma_{x y}=0$ were used to obtain $H(x)$ for $U_{o}=250 \mathrm{~m} \mathrm{yr}^{-1}$. Equation (50) for the ductile fracture model was then solved for a range of values of $d_{c}$ (the measure of the bluntness of the crack tip). The time $t_{\text {meet }}$ and distance $L_{\text {meet }}$ from the grounding line to the point where the crevasses join are summarized in Table I.

It can be seen from these results that, as $d_{c}$ increases, the accumulation rate, and therefore the ice-shelf profile, becomes less important in determining the time it takes for the cracks to meet.However, even though $d_{c}$ increases by a factor of 50 , the time to meet only decreases by a factor of two. The effect of the parameter $d_{c}$ in determining the rate at which cracks grow is minimal, which is encouraging since determining an actual value for this parameter is difficult at best.

When the analysis dealt solely with elastic fracture mechanics as the rate-determining factor, it was shown that elastic cracks propagate through ice at velocities approximating the speed of sound. Our analysis for ductile cracks in ice shelves produces cracks that propagate to complete fracture in 20 to 50 years over a distance of $5 \mathrm{~km}$ to $12 \mathrm{~km}$ from the grounding line. This, of course, ignores reduced crack propagation rates as water freezes onto cold crack walls.

\section{Conclusions}

Calving of giant icebergs from ice shelves and ice streams that fringe and drain the marine West Antarctic Ice Sheet has proliferated in this decade. As a consequence, the northern, eastern, and western margins have sustained reduced buttressing, and increased lowering of interior ice elevations has been reported (Bindschadler 1997, Shepherd et al. 2001, Zwally et al. 2002). A selective review of linear elastic fracture mechanics, following Griffith $(1920,1924)$, and dislocation based fracture mechanics, following Weertman (1996), has led to a steady-state distribution of stresses at a crack tip that depends on both elastic and ductile properties of a crystalline material, and that provides a growth law for the growth of cracks. This law is applied to a typical Antarctic ice shelf and ice stream, with crack initiation caused by longitudinal tension when velocity increases as grounded ice becomes afloat. This allows simultaneous nucleation of both top and bottom cracks that then grow toward each other and release a giant iceberg when they meet. Typical sizes of icebergs are 5 to $12 \mathrm{~km}$ in longitudinal length. This crack spacing seems to be tied to the time needed to fracture the whole ice thickness, as if tensile stresses propagate existing cracks to complete fracture before they open new cracks. They are released every 20 to 48 years. These results are only approximate, since freezing rates of water in crevasses, ice-shelf geometry, and constraints on shelf flow are not considered. In addition, release of giant icebergs also requires intersection of longitudinal and transverse crevasses, not just their vertical propagation through the ice thickness. Propagation and intersection of these crevasses entails only removal of the stress intensity factor for the ice overburden pressure in the analysis presented here, but their faster propagation rates must travel greater distances than for slower vertical crack propagation.

Without formal proof, our work encourages us to propose a General Principle of calving of giant icebergs. The externally applied gravitational tensile stress in an ice shelf is increasingly magnified in the shrinking cross-section of ice between advancing top and bottom crevasses, thereby preventing new tensile crevasses from opening until complete fracture occurs when the top and bottom crevasses meet so that the strain energy becomes redistributed through the whole ice thickness near or at the location where the crevasse first opened. This location will be a distance from the fully fractured ice determined by the ice-shelf velocity and the time needed for top and bottom crevasses to meet. If the top crevasse is not filled with water, this advance is slowed as the ice overburden pressure increases at the top crack tip. Being not affected by ice overburden pressure, propagation of transverse and longitudinal tensile cracks will continue to advance in the plane of the ice shelf until they intersect other longitudinal and transverse crevasses. When the top and bottom crevasses meet for these intersecting crevasses, a giant tabular iceberg will be released from the ice shelf.

\section{Acknowledgement}

This work was supported by NASA and by NSF, including CReSIS funding. We thank Beverly Hughes for processing 
this paper. Two referees provided guidance in tightening our manuscript and eliminating problematic speculations.

\section{References}

Anderson, J.B. 1999. Antarctic marine geology. Cambridge: Cambridge University Press, 289 pp.

BARNBY, J.T. \& NICHOLSON, R.D. 1977. Local stress and strain during crack growth by steady-state creep. Journal of Material Sciences, 12, 2099-2108.

BERRY, J.P. 1960. Some kinetic considerations of the Griffith Criterion for fracture. Journal of Mechanics and Physics of Solids, 8, 194-216.

BindSCHADLER, R. 1997. Actively surging West Antarctic ice streams and their response characteristics. Annals of Glaciology, 24, 409-414.

BindSCHADLER, R. 1998. Monitoring ice sheet behavior from space. Reviews of Geophysics, 36, 79-104.

BindsCHADLER, R. \& VoRnBerger, P. 1998. Changes in the West Antarctic Ice Sheet since 1963 from declassified satellite photography. Science, 279, 689-692.

BRoEK, D. 1978. Elementary engineering fracture mechanics. Alphen aan den Rijn: Sitjoff \& Noordhoff, 437 pp.

BRoek, D. 1988. The practical use of fracture mechanics. Boston: Kluwer Academic Publishers, 522 pp.

Conway, H., Hall, B.L., Denton, G.H., Gades, A.M., \& Waddington, E. 1999. Past and future grounding-line retreat of the West Antarctic Ice Sheet. Science, 286, 280-283.

De Angelis, H. \& SkVARKA, P. 2003. Glacier surge after ice shelf collapse. Science, 299, 1560-1562.

Doake, C.S.M. \& Vaughan, D.G. 1991. Rapid disintegration of the Wordie Ice Shelf in response to atmospheric warming. Nature, $\mathbf{3 5 0}$, 328-330.

DulaneY, E.N. \& BRACE, W.F. 1960. Velocity behavior of a growing crack. Journal of Applied Physics, 31, 2233-2236.

Evans, H.E. 1984. Mechanisms of creep fracture. Amsterdam: Elsevier, 319 pp.

FERrigno, J.G. \& Gould, W.G. 1987. Substantial changes in the coastline of Antarctica revealed by satellite imagery. Polar Record, 23, 577-583.

Glen, J.W. 1955. The creep of polycrystalline ice. Proceedings of the Royal Society of London, 228A, 519-538.

GRIFFITH, A.A. 1920. The phenomena of rupture and flow in solids. Philosophical Transactions of the Royal Society of London, 221A, 163-197.

Griffith, A.A. 1924. The theory of rupture. In Biezeno, C.B. \& Bergers, J.M., eds. Proceedings of the First International Congress on Applied Mechanics. Delft, Netherlands: J. Waltman, 54-63.

Hughes, T. 1981b. The weak underbelly of the West Antarctic Ice Sheet (letter). Journal of Glaciology, 27, 518-525.

Hughes, T. 1998. Ice sheets. New York: Oxford University Press, 343 pp.

Hutchinson, J.W. 1968. Singular behavior at end of a tensile crack in a hardening material. Journal of Mechanics and Physics of Solids, 16, 13-31.

InGLIS, C.E. 1913. Stresses in a plate due to the presence of cracks and sharp corners. Transactions of the Institute of Naval Architects, 55, 219-241.

IRwiN, G.R. 1948. Fracture dynamics. In Fracturing of metals. Cleveland: American Society for Metals, 147-166.

Kanninen, M.F. \& Popelar, C.H. 1985. Advanced fracture mechanics. New York: Oxford University Press, 563 pp.

Kenneally, J.P. \& Hughes, T.J. 2004. Fracture and back stress along the Byrd Glacier flowband on the Ross Ice Shelf. Antarctic Science, 16, 345-354.

Keys, H.J.R., JacoBs, S.S. \& BRIGHAM, L.W. 1998. Continued northward expansion of the Ross Ice Shelf, Antarctica. Annals of Glaciology, 27, 93-98.
LAWN, B. 1993. Fracture of brittle solids. Cambridge: Cambridge University Press, $384 \mathrm{pp}$.

Lazzara, M.A., JezeK, K., Scambos, T.A., MacAyeal, D.R. \& VAn DeR VEEn, C.J. 1999. On the recent calving of icebergs from the Ross Ice Shelf. Polar Geography, 23, 201-212.

Lucchitta, B.K., Smith, C.E., Bowell, J.A. \& Mullins, K.F. 1994. Velocities and mass balance of Pine Island Glacier, West Antarctica, derived from ERS-1SAR images. In The Second ERS-1 Symposium, 11-14 October 1993. Hamburg, Germany: European Space Agency (ESA SP-361), 147-151.

MacAyeal, D.R., Scambos, T.A., Hulbe, C.L. \& Fahnestock, M.A. 2003. Catastrophic ice-shelf break-up by an ice-shelf-fragment-capsize mechanism. Journal of Glaciology, 49, 22-36.

MAcAyeAL, D.R. \& Thomas, R.H. 1982. Numerical modeling of ice-shelf motion. Annals of Glaciology, 3, 189-194.

MERCER, J.H. 1978. West Antarctic Ice Sheet and $\mathrm{CO}_{2}$ greenhouse effect: a threat of disaster. Nature, 271, 321-325.

Mотт, N.F. 1948. Fracture of metals. Engineering, 165, 16-18.

MusKhelishVILI, N.I. 1953. Some basic problems on the mathematical theory of elasticity; fundamental equations, plane theory of elasticity, torsion, and bending. Gronigen: Noordhoff, 704 pp.

Nemat-Nasser, S., Granratnachai, A. \& Keer, L.M. 1979. Spacing of water-free crevasses. Journal of Geophysical Research, 84, 4611-4620.

NYE, J.F. 1957. The distribution of stress and velocity in glaciers and ice sheets. Proceedings of the Royal Society of London, 239A, 113-133.

PAterson, W.S.B. 1994. The physics of glaciers. Oxford: Pergamon Publishing, $480 \mathrm{pp}$.

RaBus, B.T., LANG, O. \& Adolphus, U. 2003. Inter-annual velocity variations and recent calving of Thwaites Glacier Tongue, West Antarctica. Annals of Glaciology, 36, 215-224.

REEH, N. 1968. On the calving of ice from floating glaciers and ice shelves. Journal of Glaciology, 7, 215-232.

Rice, J.R. \& RosengREN, G.F. 1968. Plane strain deformation near a crack tip in a power-law hardening material. Journal of Mechanics and Physics of Solids, 16, 1-12.

RignOT, E.J. 1998a. Fast recession of a West Antarctic glacier. Science, 281, 549-551.

RIGNOT, E.J. 1998b. Radar interferometry detection of hinge-line migration on Rutford Ice Stream and Carlson Inlet, Antarctica. Annals of Glaciology, 27, 25-32.

Rignot, E.J. 2001. Evidence for rapid retreat and mass loss of Thwaites Glacier, West Antarctica. Journal of Glaciology, 47, 213-222.

Rignot, E. 2002. Ice-shelf changes in Pine Island Bay, Antarctica, 1947-2000. Journal of Glaciology, 48, 247-256.

RignOT, E.J. \& JACOBS, S.S. 2002. Rapid bottom melting widespread near Antarctic Ice Sheet grounding lines. Science, 296, 2020-2023.

RignOT, E.J. \& MACAYEAL, D.R. 1998. Ice-shelf dynamics near the front of the Filchner-Ronne Ice Shelf, Antarctica. Journal of Glaciology, 44, 405-418.

Rist, M.A., SAmmonds, P.R., Murrell, S.A.F., Meredith, P.G., Doake, C.S.M., OERTER, H. \& MATSUKI, K. 1999. Experimental and theoretical fracture mechanics applied to Antarctic ice fracture and surface crevassing. Journal of Geophysical Research, 104, 2973-2987.

Rist, M.A., Sammonds, P.R., Murrell, S.A.F., Meredith, P.G., Oerter, H. \& DoAKE, C.S.M. 1996. Experimental fracture and mechanical properties of Antarctic ice: preliminary results. Annals of Glaciology, 23, 85-102.

Rist, M.A., SAmmonds, P.R., OerTer, H. \& DoAKE, C.S.M. 2002. Fracture of Antarctic shelf ice. Journal of Geophysical Research, 107, ECV 1-13.

RoBerts, D.K. \& Wells, A.A. 1954. The velocity of brittle fracture. Engineering, 178, 820-821.

Rooke, D.P. \& CARTwRight, D.J. 1976. Compendium of stress intensity factors. London: HMSO, $330 \mathrm{pp}$.

Rott, H., Skvarca, P. \& Nagler, T. 1996. Rapid collapse of northern Larsen Ice Shelf, Antarctica. Science, 271, 788-792. 
Scambos, T.A., Hulbe, C.L., Fahnestock, M.A. \& Bohlander, J. 2000. The link between climate warming and break-up of ice shelves in the Antarctic Peninsula. Journal of Glaciology, 46, 516-530.

Shepherd, A., Wingham, D.J., Mansley, J.A.D. \& CorR, H.F.J. 2001. Inland thinning of Pine Island Glacier, West Antarctica. Science 291, 862-864.

SIH, G.C. 1973a. Handbook of stress-intensity factors; stress-intensity factor solutions and formulas for reference. Bethlehem, PA: Institute of Fracture and Solid Mechanics, Lehigh University.

SiH, G.C. 1973b. Methods of analysis and solutions of crack problems. Leyden: Noordhoff International Publishing, 568 pp.

SimmONS, G. \& WANG, H. 1971. Single crystal elastic constants and calculated aggregate properties: a handbook. Cambridge, MA: The M.I.T. Press.

SмiтH, R.A. 1976. The application of fracture mechanics to the problem of crevasses penetration. Journal of Glaciology, 17, 223-228.

Swithinbank, C. 1999. Foothold on Antarctica: the First International Expedition (1949-1952) through the eyes of its youngest member. Lewes: The Book Guild, 260 pp.

TADA, H., PARIS, P.C. \& IRwIN, G.R. 1973. The stress analysis of cracks handbook. Hellertown, PA: Del Research Corporation, 677 pp.

Thomas, R.H. 1973a. The creep of ice shelves: theory. Journal of Glaciology, 12, 45-53.

Thomas, R.H. 1973a. The creep of ice shelves: interpretation of observed behaviour. Journal of Glaciology, 12, 55-70.

Thomas, R.H. \& MacAyeal, D.R. 1982. Derived characteristics of the Ross Ice Shelf. Journal of Glaciology, 28, 397-412.

Thomas, R.H., Csatho, B., Gogineni, S., JezeK, K. \& Kuivinen, K. 1998. Thickening of the western part of the Greenland ice sheet. Journal of Glaciology, 44, 653-658.
Thomas, R.H., SAnderson, T.J.O. \& Rose, K.E. 1979. Effect of climatic warming on the West Antarctic ice sheet. Nature, 277, 355-358.

VAN DER VEen, C.J. 1996. Tidewater calving. Journal of Glaciology, 42, 375-385.

VAN DER VEEN, C.J., ed. 1997. Calving glaciers: report of a workshop. Columbus, OH: Byrd Polar Research Center, The Ohio State University, 194 pp.

VAN DER VEEN, C.J. 1998a. Fracture mechanics approach to penetration of surface crevasses on glaciers. Cold Regions Science and Technology, 27, 31-47.

VAN DER VEEN, C.J. 1998b. Fracture mechanics approach to penetration of bottom crevasses on glaciers. Cold Regions Science and Technology, 27, 213-223.

VAN DER VEEN, C.J. 1999. Fundamentals of Glacier Dynamics. Rotterdam: A.A. Balkema, 462 pp.

VAUGHAN, D.G. 1993. Relating the occurrence of crevasses to surface strain rates. Journal of Glaciology, 39, 255-266.

WeErtman, J. 1973. Can a water-filled crevasse reach the bottom surface of a glacier? IAHS Publication, No 95, 139-145.

Weertman, J. 1977. Penetration depth of closely spaced water-free crevasses. Journal of Glaciology, 18, 37-46.

WeERTMAN, J. 1980. Bottom crevasses. Journal of Glaciology, 25, 185-188.

Weertman, J. 1996. Dislocation based fracture mechanics. Hackensack, NJ: World Scientific, 524 pp.

Zwally, H.J., Schultz, B., Abdalati, W., Abshire, J., Bentley, C.R., Brenner, A., Quinn, K., Palm, S., Spinhirne, J. \& Thomas, R.H. 2002. ICESat's laser measurements of polar ice, atmosphere, ocean, and land. Journal of Geodynamics, 34, 405-445. 
